\title{
Genotypic characterization of amoeba isolated from Acanthamoeba keratitis in Poland
}

\author{
Monika Derda • Piotr Solarczyk • Marcin Cholewiński • \\ Edward Hadaś
}

Received: 15 December 2014 / Accepted: 7 January 2015 /Published online: 22 January 2015

(C) The Author(s) 2015. This article is published with open access at Springerlink.com

\begin{abstract}
Free-living amoebae belonging to the genus Acanthamoeba are the causative factor of many diseases. Among others, they cause Acanthamoeba keratitis (AK), a condition that usually occurs in contact lens wearers, though it is also observed in non-wearers. The number of diagnosed cases of AK increased more than eightfold during 8 years in the USA, and a proportional increase in frequency also occurred in Poland and Europe. Cases of AK are usually diagnosed late, and their therapy is difficult and rarely successful. AK is an uncommon diagnosis in Poland. The increased number of positive cases observed in our laboratory may reflect the growing at-risk population of contact lens wearers. Acanthamoeba as a genus of facultative human parasites is currently classified into 17 genotypes. Isolates belonging to seven genotypes were found to be associated with AK. One genotype in particular, T4, was found to be overrepresented in human disease. The main finding of our study is that in Poland, AK is almost always associated with the T4 genotype.
\end{abstract}

Keywords Acanthamoeba Acanthamoeba keratitis . Cornea $\cdot$ Genotyping

\section{Introduction}

Amoebae belonging to the genus Acanthamoeba are freeliving organisms, widespread in the environment, and excellently adjusted to various environmental conditions (Stockman et al. 2011). They occur in two developmental stages: trophozoites and cysts, resistant to environmental

M. Derda $(\bowtie) \cdot$ P. Solarczyk $\cdot$ M. Cholewiński $\cdot$ E. Hadaś Department of Biology and Medical Parasitology, Poznan University of Medical Sciences, Poznan, Poland

e-mail: mderda@ump.edu.pl conditions (Marciano-Cabral and Cabral 2003). The invasive forms for the human are cysts as well as trophozoites of amoebae. Infection occurs most often in the warm seasons and is associated with contact with water. In particular cases, the infection may take place through damaged skin or accidently injured cornea, e.g., during earth works or playing with sand or water, or through contact lenses.

The most significant and most common disease caused by the free-living amoebae is Acanthamoeba keratitis (AK).

The first cases of the amoeba's invasion of the cornea were described in 1974 (Naginton et al. 1974). In subsequent years, only a few cases of AK were described. After 1981, a rapid increase in the number of cases of keratitis was observed, which reached a peak in 1985. Most cases were described in the USA.

Within the last two decades, amoebae of the Acanthamoeba genus have become a well-known and significant risk factor for the keratitis. Contributory factors include global climate warming and the increase in the population of patients with immunological deficiencies. The number of diagnosed cases of AK in the USA increased from 22 in 1999 to 170 in 2007 (Yoder et al. 2012). A proportional increase of the number of diagnosed cases of AK also occurred in Poland.

So far, apart from the USA, AK cases have been described in Europe, Australia, Asia, and Africa. The approximate number of infections is counted in thousands. The majority of cases, as many as $85-88 \%$, are connected with the wearing of contact lenses (Dart et al. 2009). Among this group, $88 \%$ of cases are connected with wearing hydrogel contact lenses and $12 \%$ with wearing rigid lenses. Seal (2003) stated that the probability of contracting AK each year is $1: 30,000$ in persons wearing contact lenses.

In persons not wearing contact lenses, AK is usually diagnosed late, and in these cases, the disease is usually already at an advanced stage. 
AK usually affects one eye. The first symptoms are blurred vision, photophobia, and severe pain in the eye not explained by corneal injury. Conjunctival swelling and eyelid swelling also appear. Patients have bleary and teary eyes. In the front layers of the corneal stroma, there are diffuse, ring-shaped, or crescent infiltrates and less specific satellite infiltrates. The ring-shaped infiltrates are single or numerous. The epithelium covering the corneal stroma can be unharmed or may have punctate erosions. In the late stage of the disease, pus appears in the eye. Together with the development of the disease, the corneal edema increases (Kosik-Bogacka et al. 2010).

\section{Material and methods}

\section{Samples of amoebae}

Eight Acanthamoeba strains were isolated from corneal scrapings from patients suspected of having keratitis. Scrapings were placed on $2 \%$ non-nutrient (NN) agar plates, covered with Enterobacter aerogenes bacteria, and the plates were incubated at a temperature of $28^{\circ} \mathrm{C}$. After 3-5 days, the increase in the number of amoebae was observed and examined with an inverted microscope at $\times 200$. The plates were monitored microscopically for up to 2 weeks for growth of Acanthamoeba trophozoites or for the presence of cysts.

\section{Pathogenicity test}

The amoebae 2-3 days old obtained from the $\mathrm{NN}$ agar culture were washed down with sterile distilled water. The suspension thus obtained was thickened and used to infect 2-week-old mice, strain BALB/c, by intranasal inoculation of five mice for each isolate. The mice were kept for 2 weeks, and thereafter anaesthetized and killed, unless they died within the first few days of being infected. The brains and lungs of the mice, irrespective of the method of death, were collected in order to isolate the amoebae. This study was conducted to verify the pathogenicity and virulence of isolated amoeba.

\section{Molecular identification}

The DNA amplification was performed using genus-specific primers previously described by Schroeder et al. (2001). A set of primers that included the forward JDPI (5'GGCCCAGATC GTTTACCGTGAA'3), and the reverse primer JDP2 were used (5'TCTCACAAGCTGCTAGGGAGTCA'3) for genetic characterization targeting the $\sim 450 \mathrm{bp}$ fragment of the Acanthamoeba $18 \mathrm{~S}$ ribosomal rRNA (rRNA) gene. Amplification involved use of a $25 \mu$ suspension of the following reagents: $2.5 \mathrm{mM} \mathrm{MgCl}_{2}, 0.6-1 \mu \mathrm{M}$ of each primer, $0.2 \mathrm{mM}$ of each deoxynucleotide triphosphate, and $0.5 \mathrm{U}$ of AmpliTaq Gold DNA polymerase. A clinical isolate of
Acanthamoeba castellanii belonging to the T4 genotype isolated from a keratitis patient (ATCC 50374) was used as a positive control. A negative control consisting of a reaction mixture without a DNA template was included. Polymerase chain reaction (PCR) was carried out using a GeneAmp 2400 thermocycler. PCR products were analyzed on $1 \%$ agarose gel stained with ethidium bromide. Gel images were illuminated using UV light and captured using a gel documentation system. PCR products were cleaned and sequenced in both directions with the same set of primers. Sequencing was performed with BigDye Terminator v3.1 on an ABI Prism 3130XL Analyzer (Applied Biosystems, USA). Trace files were checked and edited using FinchTV 1.3.1 (Geospiza Inc., Seattle, USA). Contigs were aligned and manually assembled in GeneDoc v. 2.7.000 (Nicholas and Nicholas Jr 1997; Nicholas et al. 1997). Sequencing was conducted in both directions with the same set of primers. Sequences were analyzed using the program Chromas. Next, the gene sequence fragments of the Acanthamoeba isolates were compared with the reference sequences deposited in GenBank (National Center for Biotechnology Information).

\section{Results}

\section{Pathogenicity test}

All studied isolates of amoebae were highly pathogenic and virulent. Among five infected mice, five died within 7-10 days, and the amoebae were isolated from them again.

\section{Molecular identification}

The study results of genotyping of amoebae isolates from human cases of AK from Poland are presented in Table 1. The obtained nucleotide sequences were compared with the sequences previously determined and deposited in GenBank.

It was found that all obtained sequences of amoebae isolates from the cases of AK belong to the genotype T4 Acanthamoeba sp. and were $100 \%$ identical to the sequences of the same marker obtained from environmental samples but also from people. It was also found that there are small deviations from the typical model, revealing a certain polymorphism within genotype T4. It was found that the particular amoebae isolates form three groups of nucleotide sequences are $100 \%$ identical to the model strains deposited in GenBank.

It was found that the DNA sequences of the fragment of the gene $18 S$ rRNA Ac34, Ac48, and Ac55 are $100 \%$ identical to reference sequences of the isolates of Acanthamoeba strain S6 [accession no. in GenBank DQ087296] (Yera et al. 2008), strain CCS-LG [JX441874] (Duarte et al. 2013), strain 1 FRC-2013 [KF318460] (Mafra et al. 2013), strain CDCV600 [GQ889265] (Visvesvara et al. 2010), strain 

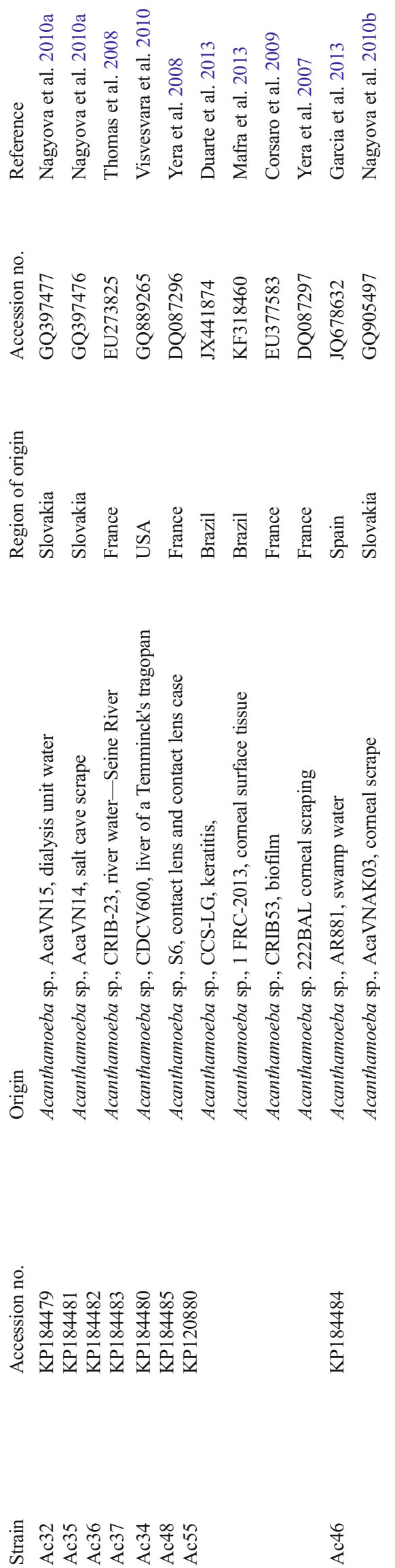

CRIB53 [EU377583] (Corsaro et al. 2009), and strain 222BAL [DQ087297] (Yera et al. 2007), originating from Brazil, the USA, and France, isolated from human cases of AK (Yera et al. 2008; Duarte et al. 2013; Mafra et al. 2013; Yera et al. 2007) as well as infected liver of Temminck's tragopan (Visvesvara et al. 2010) and the environment (Corsario et al. 2009).

The compared sequences of the Ac32, Ac35, Ac36, and Ac37 isolates from AK show $100 \%$ similarity to the sequences of the same marker obtained from environmental samples, identified as Acanthamoeba sp. of genotype T4 of such isolates as: strain AcaVN15 from dialysis unit water [GQ397477], strain AcaVN14 from salt cave scrape [GQ397476] (Nagyova et al. 2010a), and strain CRIB-23 from river water [EU273825]. The isolate Ac46 was identical in terms of nucleotide sequences to strain AR881 from swamp water [JQ678632] (Garcia et al. 2013) and strain AcaVNAK03 from corneal scrape [GQ905497] (Nagyova et al. 2010b).

Our Acanthamoeba sequences from the Ac32, Ac34, Ac35, Ac36, Ac37, Ac47, and Ac48 isolates obtained from corneal scrapings were deposited in GenBank (NCBI) under accession numbers KP184479 to KP184485.

\section{Discussion}

The omnipresence of amoeba in the surrounding environment is undeniable. These cosmopolitan organisms are found in samples of soil, air, water, and animal tissues. Acanthamoeba spp. have been isolated and identified in many countries around the world, for example in Bulgaria (Tsetkova et al. 2004), Iran (Mahmoudi et al. 2012), Spain (Magnet et al. 2012), Brazil (Duarte et al. 2013), Japan (Edagawa et al. 2009), the USA (John and Howard 1995), Switzerland (Gianinazzi et al. 2009), and also in Poland (Kasprzak and Mazur 1972).

Recognition of invading amoeba of the genus Acanthamoeba in the eye is difficult. Numerous corneal infections caused by viruses, fungi, or bacteria cause symptoms similar to amoeba infection. Very often, an infection of the eye is mistakenly diagnosed as an infection caused by herpes simplex viruses.

In the case of inflammation of the cornea caused by Acanthamoeba, there are no uniform standards for diagnostic procedures. The most common diagnostic method is culture of corneal scrapings on $\mathrm{NN}$ agar coated with bacteria (Borin et al. 2013). Methods of visualization of the cornea using confocal microscopy and immunofluorescence are also used (Aniśko-Słomińska et al. 2011; Kokot et al. 2012). Additional methods of detection include molecular analysis of nuclear and mitochondrial DNA and methods of testing restriction fragment length polymorphism analysis after digestion of DNA (Kosik-Bogacka et al. 2010). 
The taxonomy of the small amoeba species is not well established. Consequently, little is known about the genetic relationships between pathogenic and nonpathogenic strains of Acanthamoeba. During the last few years, molecular techniques (such as polymerase chain reaction-PCR) are increasingly being used in genotype identification (Booton et al. 2005; Caumo et al. 2009; Goldschmidt et al. 2012; Howe et al. 1997; Itahashi et al. 2011; Jain and Tilak 2011; Laummaunwai et al. 2012; Le Calvez et al. 2012). Our previous study confirmed the usefulness of PCR for the early, rapid, and sensitive diagnosis of pathogenic Acanthamoeba spp. strains (Derda et al. 2014). The best highly specific marker that distinguishes pathogenic Acanthamoeba strains in water samples in Poland is a pair of primers of Aca 16. The first results confirming the sensitivity and specificity of a PCR assay for the detection of AK were demonstrated by Lehmann et al. (1998), using two different pairs of primers (P1GP, P2GP). An interesting study showed that a combination of primer pairs (ACARNA, JDP, and NELSON) in the PCR-based method for diagnosing AK is more sensitive than culture and microscopy techniques (Yera et al. 2007).

Acanthamoeba as a genus of facultative human parasites is currently classified into 17 genotypes (T1-T17), each of which arguably represents a species (Stothard et al. 1998; Horn et al. 1999; Gast 2001; Hewett et al. 2003; Nuprasert et al. 2010; Corsaro and Venditti 2010).To date, isolates belonging to seven genotypes (T2, T3, T4, T5, T6, T11, and T15) have been found to be associated with AK (Stothard et al. 1998; Booton et al. 2005; Maghsood et al. 2005; Spanakos et al. 2006; Sharifi et al. 2010; Risler et al. 2013). One genotype in particular, T4, was found to be overrepresented in human disease. The main finding of our study is that in Poland, AK is almost always associated with the T4 genotype.

The correlation between Acanthamoeba genotype and clinical presentation of AK or susceptibility of the parasite to treatment has not been well explored. Khan (2003) reported that isolates belonging to AK-related genotypes exhibited significantly higher binding and cytotoxicity to corneal epithelial cells than nonclinical isolates. $\mathrm{AK}$ is an uncommon diagnosis in Poland. The increased number of positive cases observed in our laboratory may reflect the growing at-risk population of contact lens wearers. The present study was performed on a low number of isolates and may not reflect the entire spectrum of Acanthamoeba genotypes occurring in patients in Poland. However, our results indicate that the distribution of genotypes does not differ from that reported from other countries, with $\mathrm{T} 4$ as the predominant finding in $\mathrm{AK}$ cases.

Open Access This article is distributed under the terms of the Creative Commons Attribution License which permits any use, distribution, and reproduction in any medium, provided the original author(s) and the source are credited.

\section{References}

Aniśko-Słomińska J, Słomiński M, Lipowski P (2011) Mikroskopia konfokalna rogówki. Mag Lek Okul 5:309-313

Booton GC, Visvesvara GS, Byers TJ, Kelly DJ, Fuerst PA (2005) Identification and distribution of Acanthamoeba species genotypes associated with nonkeratitis infections. J Clin Microbiol 43:16891693

Borin S, Feldman I, Ken-Dror S, Briscoe D (2013) Rapid diagnosis of Acanthamoeba keratitis using non-nutrient agar with a lawn of E. coli. J Ophthalmic Inflamm Infect 3:40

Caumo K, Frasson AP, Pens CJ, Panatieri LF, Frazzon AP, Rott MB (2009) Potentially pathogenic Acanthamoeba in swimming polls: in survey in the southern Brazilian city of Porto Alegre. Ann Trop Med Parasitol 103:477-485

Corsaro D, Venditti D (2010) Phylogenetic evidence for a new genotype of Acanthamoeba (Amoebozoa, Acanthamoebida). Parasitol Res 107:233-238

Corsaro D, Feroldi V, Saucedo G, Ribas F, Loret JF, Greub G (2009) Novel Chlamydiales strains isolated from a water treatment plant. Environ Microbiol 11:188-200

Dart JK, Saw VP, Kilvington S (2009) Acanthamoeba keratitis: diagnosis and treatment update 2009. Am J Ophthalmol 148:487-499

Derda M, Wojtkowiak-Giera A, Hadaś E (2014) PCR analysis for the detection of Acanthamoeba spp. isolated from water samples. Acta Parasitol 59:472-477

Duarte JL, Furst C, Klisiowicz DR, Klassen G, Costa AO (2013) Morphological, genotypic, and physiological characterization of Acanthamoeba isolates from keratitis patients and the domestic environment in Vitoria, Espírito Santo, Brazil. Exp Parasitol 135:9-14

Edagawa A, Kimura A, Kawabuchi-Kurata T, Kusuhara Y, Karanis P (2009) Isolation and genotyping of potentially pathogenic Acanthamoeba and Naegleria species from tap-water sources in Osaka, Japan. Parasitol Res 105:1109-1117

Garcia A, Goñi P, Cieloszyk J, Fernandez MT, Calvo-Beguería L, Rubio E, Fillat MF, Peleato ML, Clavel A (2013) Identification of freeliving amoebae and amoeba-associated bacteria from reservoirs and water treatment plants by molecular techniques. Environ Sci Technol 47:3132-3140

Gast RJ (2001) Development of an Acanthamoeba-specific reverse dotblot and the discovery of a new ribotype. J Eukaryot Microbiol 48: 609-615

Gianinazzi C, Schild M, Wuthrich F, Ben Nouir N, Fuchslin HP, Schurch N, Gottstein B, Muller N (2009) Screening Swiss water bodies for potentially pathogenic free-living amoebae. Res Microbiol 160: 367-374

Goldschmidt P, Degorge S, Benallaoua D, Batellier L, Di Cave D, Chaumeil C (2012) Rapid detection and simultaneous molecular profile characterization of Acanthamoeba infections. Diagn Microbiol Infect Dis 74:137-141

Hewett MK, Robinson BS, Monis PT, Saint CP (2003) Identification of a new Acanthamoeba 18S rRNA gene sequence type, corresponding to the species Acanthamoeba jacobsi Sawyer, Nerad and Visvesvara, 1992 (Lobosea: Acanthamoebidae). Acta Protozool 42:325-329

Horn M, Fritsche TR, Gautom RK, Schleifer KH, Wagner M (1999) Novel bacterial endosymbionts of Acanthamoeba spp. related to the Paramecium caudatum symbiont Caedibacter caryophilus. Environ Microbiol 1:357-367

Howe DK, Vodkin MH, Novak RJ, Visvesvara G, McLaughlin GL (1997) Identification of two genetic markers that distinguish pathogenic and nonpathogenic strains of Acanthamoeba spp. Parasitol Res 83:345-348 
Itahashi M, Higaki S, Fukuda M, Mishima H, Shimomura Y (2011) Utility of real-time polymerase chain reaction in diagnosing and treating Acanthamoeba keratitis. Cornea 30:1233-1237

Jain R, Tilak V (2011) Primary amoebic meningoencephalitis due to Naegleria fowleri. J Indian Med Assoc 109:500-501

John DT, Howard MJ (1995) Seasonal distribution of pathogenic freeliving amebae in Oklahoma waters. Parasitol Res 81:193-201

Kasprzak W, Mazur T (1972) Free-living amoeba isolated from waters frequented by people in the vicinity of Poznań, Poland. Experimental studies in mice on the pathogenicity of the isolates. Z Tropenmed Parasitol 23:391-398

Khan NA (2003) Pathogenesis of Acanthamoeba infections. Microb Pathog 34:277-285

Kokot J, Dobrowolski D, Lyssek-Boroń A, Milka M, Smędowski A, Wójcik $Ł$, Wowra B, Wylęgała E (2012) Nowe podejście do diagnostyki i leczenia zapaleń rogówki wywołanych przez Acanthamoeba sp. -. Klin Ocz 114:311

Kosik-Bogacka D, Czepita D, Łanocha N (2010) Pełzaki z rodzaju Acanthamoeba jako czynnik etiologiczny zapalenia rogówki oka. Klin Ocz 112:161-164

Laummaunwai P, Ruangjirachuporn W, Boonmars T (2012) A simple PCR condition for detection of a single cyst of Acanthamoeba species. Parasitol Res 110:1569-1572

Le Calvez T, Trouilhe MC, Humeau P, Moletta-Denat M, Frere J, Hechard Y (2012) Detection of free-living amoebae by using multiplex quantitative PCR. Mol Cell Probes 26:116-120

Lehmann OJ, Green SM, Morlet N, Kilvington S, Keys MF, Matheson MM, Dart JK, McGill JI, Watt PJ (1998) Polymerase chain reaction analysis of corneal epithelial and tear samples in the diagnosis of Acanthamoeba keratitis. Invest Ophthalmol Vis Sci 39:1261-1265

Mafra CS, Carrijo-Carvalho LC, Chudzinski-Tavassi AM, Taguchi FM, Foronda AS, Carvalho FR, de Freitas D (2013) Antimicrobial action of biguanides on the viability of Acanthamoeba cysts and assessment of cell toxicity. Invest Ophthalmol Vis Sci 54:6363-6372

Maghsood AH, Sissons J, Rezaian M, Nolder D, Warhurst D, Khan NA (2005) Acanthamoeba genotype T4 from the UK and Iran and isolation of the T2 genotype from clinical isolates. J Med Microbiol 54: 755-759

Magnet A, Galvan AL, Feney S, Izquierdo F, Rueda C, Fernandez VC, Perez-Irezabal J, Bandyopadhyay K, Visvesvara GS, da Silva AJ, del Aquila C (2012) Molecular characterization of Acanthamoeba isolated in water treatment plants and comparison with clinical isolates. Parasitol Res 111:383-392

Mahmoudi MR, Taghipour N, Eftekhar M, Haghighi A, Karanis P (2012) Isolation of Acanthamoeba species in surface waters of Gilan province-north of Iran. Parasitol Res 110:473-477

Marciano-Cabral F, Cabral G (2003) Acanthamoeba spp. as agents of disease in humans. Clin Microbiol Rev 16:273-307

Naginton J, Watson PG, Playfair TJ, McGill J, Jones BR, Steele AD (1974) Amoebic infection of the eye. Lancet 2:1537-1540

Nagyova V, Nagy A, Janecek S, Timko J (2010a) Morphological, physiological, molecular and phylogenetic characterization of new environmental isolates of Acanthamoeba spp. from the region of Bratislava, Slovakia. Biologia 65:81-91

Nagyova V, Nagy A, Timko J (2010b) Morphological, physiological and molecular biological characterisation of isolates from first cases of Acanthamoeba keratitis in Slovakia. Parasitol Res 106:861-872

Nicholas KB, Nicholas HB Jr. (1997) GeneDoc: a tool for editing and annotating multiple sequence alignments. Distributed by the author (www.cris.com/ketchup/genedoc.shtml)
Nicholas KB, Nicholas HB Jr, Deerfield DWI (1997) GeneDoc: analysis and visualization of genetic variation. EMBNETnews 4:1-22

Nuprasert W, Putaporntip C, Pariyakanok L, Jongwutiwes S (2010) Identification of a novel T17 genotype of Acanthamoeba from environmental isolates and T10 genotype causing keratitis in Thailand. J Clin Microbiol 48:4636-4640

Risler A, Coupat-Goutaland B, Pélandakis M (2013) Genotyping and phylogenetic analysis of Acanthamoeba isolates associated with keratitis. Parasitol Res 112:3807-3816

Schroeder JM, Booton GC, Hay J, Niszl IA, Seal DV, Markus MB, Fuerst PA, Byers TJ (2001) Use of subgenic 18S ribosomal DNA PCR and sequencing for genus and genotype identification of Acanthamoebae from humans with keratitis and from sewage sludge. J Clin Microbiol 39:1903-1911

Seal DV (2003) Acanthamoeba keratitis update-incidence, molecular epidemiology and new drugs for treatment. Eye 17:893-905

Sharifi N, Botero-Kleiven S, Ohman D, Barragan A, Winiecka-Krusnell J (2010) Genotypic characterization of Acanthamoeba spp. causing ocular infections in Swedish patients: Identification of the T15 genotype in a case of protracted keratitis. Scand J Infect Dis 42:781786

Spanakos G, Tzanetou K, Miltsakakis D, Patsoula E (2006) Genotyping of pathogenic Acanthamoebae isolated from clinical samples in Greece-report of a clinical isolate presenting T5 genotype. Parasitol Int 55:147-149

Stockman LJ, Wright CJ, Visvesvara GS, Fields BS, Beach MJ (2011) Prevalence of Acanthamoeba spp. and other free-living amoebae in household water, Ohio, USA -1990-1992. Parasitol Res 108:621627

Stothard DR, Schroeder-Diedrich JM, Awwad MH, Gast RJ, Ledee DR, Rodriguez-Zaragoza S, Dean CL, Fuerst PA, Byers TJ (1998) The evolutionary history of the genus Acanthamoeba and the identification of eight new $18 \mathrm{~s}$ rRNA gene sequence types. J Eukaryot Microbiol 45:45-54

Thomas V, Loret JF, Jousset M, Greub G (2008) Biodiversity of amoebae and amoebae-resisting bacteria in a drinking water treatment plant. Environ Microbiol 10:2728-2745

Tsetkova N, Schild M, Panaiotov S, Kurdova-Mintcheva R, Gottstein B, Walochnik J, Aspock H, Lucas MS, Muller N (2004) The identification of free-living environmental isolates of amoebae from Bulgaria. Parasitol Res 92:405-413

Visvesvara GS, Shoff ME, Sriram R, Booton GC, Crary M, Fuerst PA, Hanley CS, Garner MM (2010) Isolation, morphologic, serologic and molecular identification of Acanthamoeba T4 genotype from the liver of a Temminck's tragopan (Tragopan temminckii). Vet Parasitol 170:197-200

Yera H, Zamfir O, Bourcier T, Ancelle T, Batellier L, Dupouy-Camet J, Chaumeil C (2007) Comparison of PCR, microscopic examination and culture for the early diagnosis and characterization of Acanthamoeba isolates from ocular infections. Eur J Clin Microbiol Infect Dis 26:221-224

Yera H, Zamfir O, Bourcier T, Viscogliosi E, Noël C, Dupouy-Camet J, Chaumeil C (2008) The genotypic characterisation of Acanthamoeba isolates from human ocular samples. $\mathrm{Br} \mathrm{J}$ Ophthalmol 92:1139-1141

Yoder JS, Verani J, Heidman N, Hoppe-Bauer J, Alfonso EC, Miller D, Jones DB, Bruckner D, Langston R, Jeng BH, Joslin CE, Tu E, Colby K, Vetter E, Ritterband D, Mathers W, Kowalski RP, Acharya NR, Limaye AP, Leiter C, Roy S, Lorick S, Roberts J, Beach MJ (2012) Acanthamoeba keratitis: the persistence of cases following a multistate outbreak. Ophthalmic Epidemiol 19:221-225 